\title{
Choline Metabolism Alteration: A Focus on Ovarian Cancer
}

\author{
Marina Bagnoli ${ }^{*}$, Anna Granata', Roberta Nicoletti', Balaji Krishnamachary'2, \\ Zaver M. Bhujwalla², Rossella Canese ${ }^{3}$, Franca Podo ${ }^{3}$, Silvana Canevari ${ }^{1,4}$, Egidio Iorio ${ }^{3}$ \\ and Delia Mezzanzanica ${ }^{1 *}$
}

'Unit of Molecular Therapies, Department of Experimental Oncology and Molecular Medicine, Fondazione IRCCS Istituto Nazionale dei Tumori, Milan, Italy, ${ }^{2}$ Russell H. Morgan Department of Radiology and Radiological Science, Division of Cancer Imaging Research, In Vivo Cellular and Molecular Imaging Center, The Johns Hopkins University School of Medicine, Baltimore, MD, USA, ${ }^{3}$ Department of Cell Biology and Neurosciences, Istituto Superiore di Sanità, Rome, Italy, ${ }^{4}$ Functional Genomics and Informatics, Department of Experimental Oncology and Molecular Medicine, Fondazione IRCCS Istituto Nazionale dei Tumori, Milan, Italy

\section{OPEN ACCESS}

Edited by:

Giuseppe Esposito,

Medstar Georgetown University Hospital, USA

Reviewed by: Orazio Schillaci, University of Rome Tor Vergata, Italy Luigi Aloj,

Cambridge University Hospitals, UK Corina Millo,

National Institutes of Health, USA

${ }^{*}$ Correspondence:

Marina Bagnol marina.bagnoli@istitutotumori.mi.it; Delia Mezzanzanica delia.mezzanzanica@istitutotumori.

Specialty section:

This article was submitted to

Cancer Imaging and

Diagnosis, a section of the journal Frontiers in Oncology

Received: 10 March 2016 Accepted: 07 June 2016

Published: 22 June 2016

Citation: Bagnoli M, Granata A, Nicoletti R, Krishnamachary $B$, Bhujwalla ZM, Canese R, Podo F, Canevari S, Iorio E and Mezzanzanica D (2016)

Choline Metabolism Alteration: A Focus on Ovarian Cancer.

Front. Oncol. 6:153. doi: 10.3389/fonc.2016.00153
Compared with normal differentiated cells, cancer cells require a metabolic reprograming to support their high proliferation rates and survival. Aberrant choline metabolism is a fairly new metabolic hallmark reflecting the complex reciprocal interactions between oncogenic signaling and cellular metabolism. Alterations of the involved metabolic network may be sustained by changes in activity of several choline transporters as well as of enzymes such as choline kinase-alpha (ChoK- $\alpha)$ and phosphatidylcholine-specific phospholipases $\mathrm{C}$ and $\mathrm{D}$. Of note, the net outcome of these enzymatic alterations is an increase of phosphocholine and total choline-containing compounds, a "cholinic phenotype" that can be monitored in cancer by magnetic resonance spectroscopy. This review will highlight the molecular basis for targeting this pathway in epithelial ovarian cancer (EOC), a highly heterogeneous and lethal malignancy characterized by late diagnosis, frequent relapse, and development of chemoresistance. Modulation of ChoK- $\alpha$ expression impairs only EOC but not normal ovarian cells, thus supporting the hypothesis that "cholinic phenotype" is a peculiar feature of transformed cells and indicating ChoK- $\alpha$ targeting as a novel approach to improve efficacy of standard EOC chemotherapeutic treatments.

Keywords: choline kinase, ovarian cancer, phosphocholine metabolism, reversal of drug resistance, antioxidant defense

\section{INTRODUCTION}

The uncontrolled cell growth characteristic of neoplastic diseases, besides involving deregulated control of cell proliferation, requires an adjustment of energy metabolism to sustain cell growth and division. Altered energy metabolism is considered as widespread in cancer cells as other cancerassociated characteristics. Reprograming of cell metabolism has been therefore included among cancer hallmarks (1), a series of biological properties acquired by tumor cells during transformation and disease progression. Metabolites themselves can interfere with oncogenic-driven cell signaling (2) and, since cancer cells are dependent on these changes in metabolism, these altered pathways represent attractive sources of promising therapeutic targets $(3,4)$. Furthermore, the differential uptake in some human cancers of glucose, choline, acetate, methionine, and aminoacid analogs, when used 
as radiotracers in positron emission tomography (PET) imaging, is considered a clinically useful diagnostic/staging tool (4).

\section{CHOLINE METABOLISM ALTERATION IN HUMAN CANCER}

Aberrant choline metabolism, characterized by increased phosphocholine (PCho) and total choline-containing compounds (tChos), is a fairly new metabolic hallmark that can be monitored in cancer by magnetic resonance spectroscopy (MRS) and that reflects the complex reciprocal interactions between oncogenic signaling and cellular metabolism $(5,6)$. PCho is both a precursor and a breakdown product of phosphatidylcholine (PC), one of the major components of cellular membranes. Indeed, the PCho content is sustained by activation of enzymes involved in PC biosynthetic and catabolic pathways: choline kinase (ChoK) and PC-specific phospholipase C (PC-PLC) (Figure 1A). ChoK is the first enzyme of the Kennedy pathway responsible for catalyzing the phosphorylation of free choline to form PCho in the biosynthesis of PC (7). Three isoforms of ChoK are present in mammalian cells encoded by two different genes: choline kinasealpha $(C H K A)$ and choline kinase-beta $(C H K B)$. However, only ChoK-alpha (ChoK- $\alpha$ ) has a central role in sustaining PC biosynthesis required for the uncontrolled growth of cancer cells, and ChoK- $\beta$ alone cannot compensate this activity (8). In addition to its metabolic function, ChoK- $\alpha$ has been proven to play a critical role in oncogenesis, tumor progression, and metastasis of several cancers being required for the activation of growth factor-triggered signaling pathways (Ras activation, PI3K signaling), roles that proposed CHKA as an oncogene (5, 9-11). Indeed, an altered choline metabolism, sustained by increased expression and activity of $\mathrm{ChoK}-\alpha$, has been reported in various human malignancies (12-19). Furthermore, in the case of early stage non-small cell lung cancer (20), early stage hepatocellular carcinoma (21), and prostate cancer (22), a prognostic role of ChoK- $\alpha$ overexpression has been revealed. These observations provided the molecular basis for the development of noninvasive imaging approaches based on choline phosphorylation for the characterization of tumor growth and response to therapy (23-26) as well as the rationale for developing specific inhibitors for this metabolic pathway even in diseases other than cancer $(27,28)$.

\section{CHOLINE KINASE AS A POTENTIALLY NEW THERAPEUTIC TARGET FOR CANCER TREATMENT}

Choline kinase- $\alpha$ is an enzyme of particular interest being at the crossroad of the main survival signaling pathways with its overexpression contributing, through a positive feedback loop, to increased MAPK and PI3K signaling $(5,29)$. A large body of work in cancer cells suggests that ChoK- $\alpha$ expression and activity is directly associated not only with increased cancer cell proliferation but also with malignancy, making it a potential novel target for image-guided cancer therapy. In fact, the targeting of ChoK- $\alpha$ by RNA interference (RNAi) results in decreased PCho and tCho levels in human breast cancer cells while leaving human mammary epithelial cells unaffected $(30,31)$, thus opening an important therapeutic window for the development of a pharmacological intervention directed to this enzyme $(32,33)$. Indeed, the antitumor effects of ChoK- $\alpha$ inhibition has been reported in various cancers (34-40). Different compounds are at the moment available for ChoK- $\alpha$ pharmacological inhibition: hemicholinium-3 (HC-3), a competitive inhibitor with a ChoK- $\alpha$ mimetic structure able to block also choline transport, is very efficient in vitro but highly toxic in vivo (41); MN-58b, not commercially available, is a

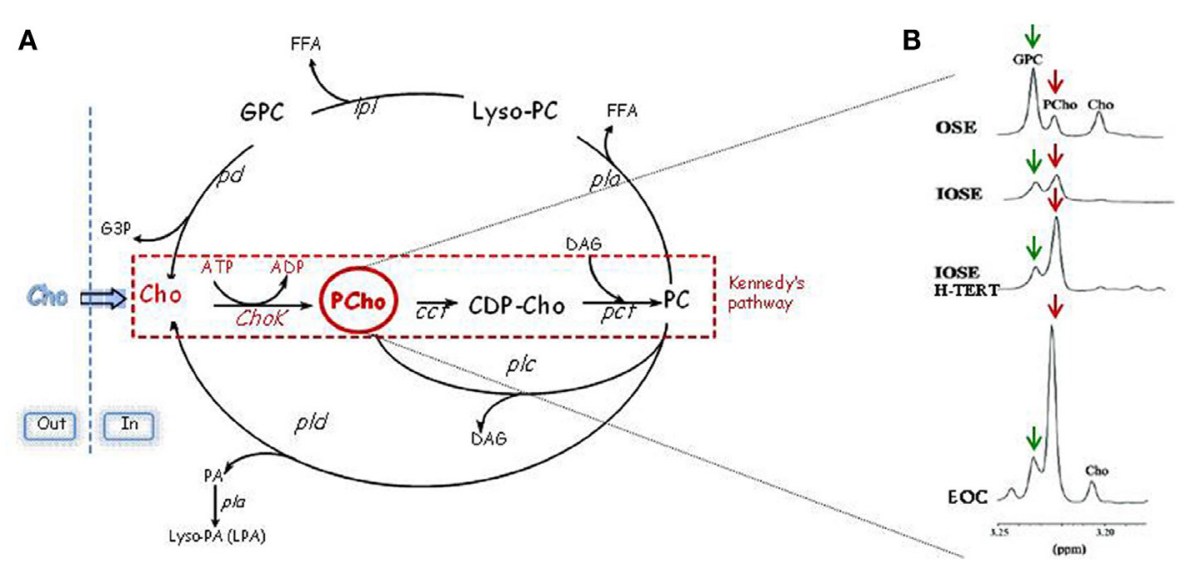

FIGURE 1 | Schematic representation of PC cycle and routes of PCho accumulation. (A) Kennedy's pathway: Cho, choline; Chok, choline kinase; PCho, phosphocholine; CCT, cytidylyltransferase; CDP-Cho, cytidine diphosphate-choline; PCT, phosphocholine phosphotransferase; DAG, diacylglycerol; PC: phosphatidylcholine. Catabolic pathways: PLC, PC-specific phospholipase C; PLD, PC-specific phospholipase D; PLA, PC-specific phospholipases A2 and A1; PD, phosphodiesterase; GPC, glycerophosphocholine; PA, phosphatidate. (B) In the progression from non-tumoral ovarian surface epithelial cells (OSE) or immortalized cell variants (IOSE with an increased replicative potential and IOSE-HTERT with unlimited replicative potential) to EOC cells, there is an evident accumulation of PCho (red arrows) and a decrease of GPC (green arrows). 
less toxic HC-3 derivative able to inhibit cell growth in vivo in animal models (42); RSM-932A, a Chok- $\alpha$ inhibitor selected for further clinical development due to its potent in vivo anticancer activity and lack of toxicity at the effective doses (43); CK37, a small molecule able to inhibit tumor growth in preclinical models (44); and new small molecule inhibitors identified by fragment-based drug discovery (45). These data suggest that inhibiting $\mathrm{ChoK}-\alpha$, even in combination with standard chemotherapeutic treatments, might represent a new anticancer approach particularly in tumors such as ovarian cancer with a still open clinical need for the identification of more efficient therapeutic modalities.

\section{OVARIAN CANCER}

Epithelial ovarian cancer (EOC) is a life-threatening disease characterized by late-stage presentation and a distinctive ability to heavily invade the abdominal cavity (46). The yearly worldwide incidence of this cancer is of 238,700 new cases with a global mortality of 151,900 deaths per year (47), which make EOC the leading cause of death for gynecological cancers. Standard treatment for EOC patients is an aggressive primary surgery followed by platinum-based chemotherapy. However, around 30\% of the patients undergo chemotherapeutic treatments before being identified as chemoresistant, and even for patients who achieve a pathological complete response, maintaining disease-free status remains a challenge. Indeed, most of the patients develop platinum-resistant recurrent disease, a largely incurable state. Despite the impressive improvement of surgical approaches and drug development, survival rate has changed little in the last decades (48), and 5-year survival rate for advanced stage patients is still around $30 \%$ (49).

It is well known that resistance to chemotherapy is one of the tumor "hallmarks" that also includes tumor ability to modify/ reprogram cellular metabolism (1) to face with the biosynthetic demand of rapid proliferation and to overcome metabolic stress imposed by the microenvironment. As for many other cancer types, also EOC cells become dependent on these metabolic changes, which could be possibly exploited to identify therapeutic targets for overcoming chemoresistance.

\section{TARGETING THE ALTERED CHOLINE METABOLISM TO EVADE/CIRCUMVENT EOC CHEMORESISTANCE}

Aberrant choline metabolism has been recently defined also in EOC. Analysis of expanded tCho MR spectral profiles showed that the relative areas of signal components due to individual choline metabolites [glycerophosphocoline (GPC), PCho, and free choline] changed in the progression from non-tumoral ovarian surface epithelial cells (OSE) or immortalized cell variants to EOC cells (15), with the PCho relative signal becoming predominant in carcinoma cells (Figure 1B).

A large body of work demonstrated that, in EOC, these alterations are sustained by the activation of two enzymes ChoK- $\alpha$ and PC-PLC, respectively, involved in the PC biosynthetic and catabolic pathway. ChoK- $\alpha$ has a major role in increasing PCho content. Indeed, ChoK- $\alpha$ is overexpressed and hyperactivated in EOC cells as compared with the normal counterpart, accounting for up to the $70-80 \%$ of the total intracellular PCho content $(16,37)$. Gene expression analysis of the enzymes involved in the PC anabolic pathway showed that only CHKA was overexpressed, whereas the expression of other enzymes involved in the Kennedy pathway, as well as the beta isoform of choline kinase $(\mathrm{CHKB})$, choline transporters, and enzymes involved in some catabolic pathways (mediated by PLD, PLA1, and PLA2) remained essentially unchanged (16). Among the enzymes involved in catabolic pathways, only PC-PLC is directly involved in PCho production. Although the mammalian PC-PLC has not been currently cloned and its sequence is unknown, this enzyme has been shown to be overexpressed and hyperactivated in EOC cells compared with normal counterparts $(16,50)$. EOC cells exposure to the PC-PLC inhibitor D609 abolished the activity of this enzyme and reduced the intracellular PCho level (without altering GPC and free choline contents), suggesting that also PC-PLC partially contributes to the intracellular PCho pool in $\operatorname{EOC}(16,50)$.

To define the role of the abnormal expression and increased activation of ChoK- $\alpha$ in EOC biology, the enzyme was inactivated by transient and stable RNA interference in EOC cell lines and in non-tumoral immortalized cell variants. ChoK- $\alpha$ inhibition resulted in a less aggressive phenotype $(36,37)$, causing a decreased cell proliferation both in vitro and in preclinical in vivo models of $\mathrm{Nu} / \mathrm{Nu}$ mice, an impaired capability to migrate and invade, together with an increased sensitivity to drug treatment of EOC cells (Figure 2).

The effects related to CHKA targeting in EOC appeared to induce a perturbation on EOC cell behavior different than that observed in other cellular models. In fact, neither previously described reduction of Akt phosphorylation in a PI3Kindependent way (51) nor an attenuation of MAPK and PI3K/ AKT signaling (29) was observed. Furthermore, in spite of a reduced cell proliferation, neither a decrease of cell viability nor apoptosis was detected in CHKA-silenced EOC cells.

On the other hand, the analysis of global metabolic profiling identified an altered glutathione (GSH) metabolism characterized by a decreased cysteine and GSH content (37). GSH is a thiol peptide involved in regulation of cell redox status through its antioxidant activities (52). Reduction of GSH content, perturbing redox homeostasis, is expected to render tumor cells more susceptible to chemotherapeutic treatment (Figure 2), and high intracellular levels of reduced GSH have been shown to contribute in developing resistance to chemotherapeutic drugs including platinum and doxorubicin (53-55). Accordingly, CHKA targeting in different EOC cellular models increased reactive oxygen species (ROS) intracellular levels and sensitivity to platinum and doxorubicin treatment. These effects were mediated by the reduction of GSH content, even in a drug resistant EOC model, while leaving unaffected the non-tumoral immortalized epithelial ovarian cells (37) (Figure 2).

Interestingly, the critical enzyme cleaving GPC to produce choline, the initial step in the pathway controlling the GPC/ $\mathrm{PC}$ ratio, has been recently identified (56). The enzyme, named 


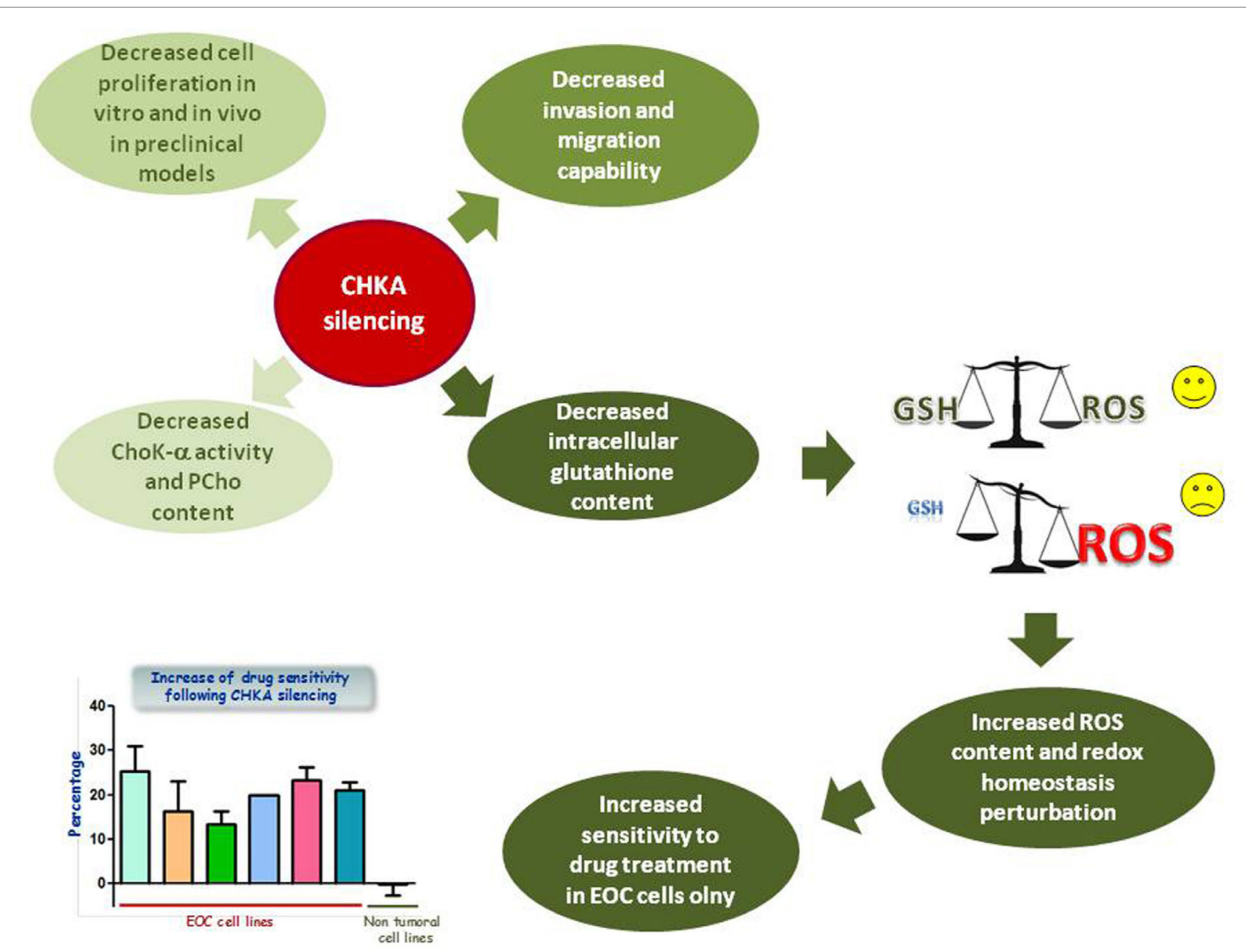

FIGURE 2 | Effects of CHKA silencing in EOC cell lines. CHKA silencing decreases cell proliferation in vitro and in vivo in preclinical models, impairs the capability of EOC cells to migrate and invade, and decreases levels of intracellular GSH, thus impairing cellular redox homeostasis and therefore increasing EOC, but not IOSE-HTERT sensitivity to platinum treatment.

endometrial differential 3 (EDI3), was initially described in a breast cancer cell line, where its inhibition corrected the GPC/PC ratio and reduced migratory activity of tumor cells. Also, EDI3 overexpression was associated with higher risk of developing metastasis and decreased survival in endometrial and ovarian cancer (56). The recent finding that EDI3 links choline metabolism to integrin expression, cell adhesion, and spreading also in an EOC cell line (57), suggests EDI3 as a new possible target to be explored, further confirming the value of the choline metabolism for therapeutic intervention in EOC.

The EOC "cholinic phenotype" is a peculiar feature of transformed cells that recapitulates the addiction of EOC cells to GSH content for the maintenance of their antioxidant defense. Targeting mechanisms upon which cancer cells are expected to be dependent (CHKA expression and cellular ROS homeostasis) could explain the differential response of cancer and non-transformed cells to CHKA knockdown. As well known, cancer cells acquire specific genetic and epigenetic alterations that involve hyperactivation of oncogenes and/or inactivation of oncosuppressor genes. Some genetic changes support survival of cancer cells by creating specific signaling, which sustain metabolic pathways. However, the overall deregulation of cellular processes and functions is frequently associated with enhanced cellular stress, and malignant cells have to adapt to this phenotype, becoming dependent on a number of non-oncogenic functions to survive (3). Similarly, a dependency associated with ROS homeostasis has been shown to constitute a selective liability of malignant cells also in xenograft tumor models (58). Identifying such dependencies represent a promising alternative for the development of new therapeutic strategies to successfully target metabolic enzymes minimizing adverse effects on normal tissues. Synergisms of choline metabolism knockdown with conventional treatment might open an interesting clinical perspective, as it could represent an alternative strategy to increase the treatment efficacy also by reducing the clinical dose of drugs and limiting the damage of normal cells. 


\section{EXPLOITING THE ALTERED CHOLINE METABOLISM FOR THE IN VIVO IMAGING OF TUMOR RESPONSE TO THERAPIES}

Due to the increased metabolic activity, tumors are expected to intake greater amounts of a radioactive tracer than the adjacent normal tissues, justifying the use of PET imaging to monitor response to treatment and disease recurrence (59). Accordingly, the increased expression and activity of ChoK- $\alpha$ and choline transporters in tumor cells promoted a rapid development of radiolabeled choline analogs, as PET imaging tracers and ${ }^{11} \mathrm{C}$ - or ${ }^{18} \mathrm{~F}$-choline were proven to be more effective than ${ }^{18} \mathrm{~F}$-fluorodeoxyglucose (FDG), whose abundant radioactivity excretion into the bladder could hamper image interpretation. Indeed, in the case of radiolabeled choline analogs, their incorporation mainly reflects the total amount of radiotracer that enters the cell by choline transport and accumulates, by efficient phosphorylation mainly due to ChoK activation, in the pool of water-soluble intermediates of the Kennedy pathway (24). Within the time window of choline PET examinations, the contributions given by PC catabolic enzymes (such as phospholipases $\mathrm{C}$ and D) to the pool of these radiolabeled choline derivatives are instead negligible (6).

The large proportion of studies evaluating choline radiotracers has been conducted in prostate cancer where choline PET gave a clinical contribution in the diagnosis and monitoring of response to therapy; however, the utility of ${ }^{11} \mathrm{C}$ - or ${ }^{18} \mathrm{~F}$-choline as radiotracers has been extensively reported also in non-prostate

\section{REFERENCES}

1. Hanahan D, Weinberg RA. Hallmarks of cancer: the next generation. Cell (2011) 144:646-74. doi:10.1016/j.cell.2011.02.013

2. Ward PS, Thompson CB. Metabolic reprogramming: a cancer hallmark even Warburg did not anticipate. Cancer Cell (2012) 21:297-308. doi:10.1016/j. ccr.2012.02.014

3. Galluzzi L, Kepp O, Vander Heiden MG, Kroemer G. Metabolic targets for cancer therapy. Nat Rev Drug Discov (2013) 12:829-46. doi:10.1038/nrd4145

4. Vander Heiden MG. Targeting cancer metabolism: a therapeutic window opens. Nat Rev Drug Discov (2011) 10:671-84. doi:10.1038/nrd3504

5. Glunde K, Bhujwalla ZM, Ronen SM. Choline metabolism in malignant transformation. Nat Rev Cancer (2011) 11:835-48. doi:10.1038/nrc3162

6. Podo F, Canevari S, Canese R, Pisanu ME, Ricci A, Iorio E. MR evaluation of response to targeted treatment in cancer cells. NMR Biomed (2011) 24:648-72. doi:10.1002/nbm.1658

7. Wu G, Vance DE. Choline kinase and its function. Biochem Cell Biol (2010) 88:559-64. doi:10.1139/O09-160

8. Wu G, Aoyama C, Young SG, Vance DE. Early embryonic lethality caused by disruption of the gene for choline kinase alpha, the first enzyme in phosphatidylcholine biosynthesis. J Biol Chem (2008) 283:1456-62. doi:10.1074/jbc. M708766200

9. Ramirez de Molina A, Gallego-Ortega D, Sarmentero J, Banez-Coronel M, Martin-Cantalejo Y, Lacal JC. Choline kinase is a novel oncogene that potentiates RhoA-induced carcinogenesis. Cancer Res (2005) 65:5647-53. doi:10.1158/0008-5472.CAN-04-4416

10. Gallego-Ortega D, Ramirez de Molina A, Ramos MA, Valdes-Mora F, Barderas MG, Sarmentero-Estrada J, et al. Differential role of human choline kinase alpha and beta enzymes in lipid metabolism: implications in cancer onset and treatment. PLoS One (2009) 4:e7819. doi:10.1371/journal.pone.0007819

11. Gallego-Ortega D, del PT, Valdes-Mora F, Cebrian A, Lacal JC. Involvement of human choline kinase alpha and beta in carcinogenesis: a different role in lipid histotypes $(24,59)$. Although studies on ${ }^{11} \mathrm{C}$ - or ${ }^{18} \mathrm{~F}$-choline as radiotracers in PET examinations of genitourinary tract cancers are currently under active evaluation as an alternative to ${ }^{18} \mathrm{~F}-\mathrm{FDG}$, few studies are currently available on the use of choline-based tracer in ovarian cancer, even at preclinical level $(60,61)$.

In spite of the EOC cholinic phenotype, a choline-based noninvasive detection and management is still a relatively unexplored field in this disease. An improvement in instrumentation and the integration of different imaging approaches, such as PET, magnetic resonance imaging (MRI), and computed tomography (CT), could provide the unique opportunity to monitor both morphologic and metabolic changes in tumor to improve diagnosis and the assessment of therapeutic efficacy.

\section{AUTHOR CONTRIBUTIONS}

All the authors have contributed in writing this mini review and have been directly involved in obtaining the results described in the chapter dedicated to ovarian cancer and choline metabolism. All the authors reviewed the manuscript and approved the final version.

\section{ACKNOWLEDGMENTS}

The authors are grateful to the Associazione Italiana per la Ricerca sul Cancro (AIRC, IG-9147, IG-12976, and IG-17475) and to the Ministero della Salute grant RF-2010-2313497 for partially supporting these studies. metabolism and biological functions. Adv Enzyme Regul (2011) 51:183-94. doi:10.1016/j.advenzreg.2010.09.010

12. Nakagami K, Uchida T, Ohwada S, Koibuchi Y, Suda Y, Sekine T, et al. Increased choline kinase activity and elevated phosphocholine levels in human colon cancer. Jpn J Cancer Res (1999) 90:419-24. doi:10.1111/j.1349-7006.1999. tb00698.x

13. Ramirez de Molina A, Rodriguez-Gonzalez A, Gutierrez R, Martinez-Pineiro L, Sanchez J, Bonilla F, et al. Overexpression of choline kinase is a frequent feature in human tumor-derived cell lines and in lung, prostate, and colorectal human cancers. Biochem Biophys Res Commun (2002) 296:580-3. doi:10.1016/ S0006-291X(02)00920-8

14. Ramirez de Molina A, Gutierrez R, Ramos MA, Silva JM, Silva J, Bonilla F, et al. Increased choline kinase activity in human breast carcinomas: clinical evidence for a potential novel antitumor strategy. Oncogene (2002) 21:4317-22. doi:10.1038/sj.onc.1205556

15. Iorio E, Mezzanzanica D, Alberti P, Spadaro F, Ramoni C, D’Ascenzo S, et al. Alterations of choline phospholipid metabolism in ovarian tumor progression. Cancer Res (2005) 65:9369-76. doi:10.1158/0008-5472.CAN05-1146

16. Iorio E, Ricci A, Bagnoli M, Pisanu ME, Castellano G, Di Vito M, et al. Activation of phosphatidylcholine cycle enzymes in human epithelial ovarian cancer cells. Cancer Res (2010) 70:2126-35. doi:10.1158/0008-5472. CAN-09-3833

17. Hernando E, Sarmentero-Estrada J, Koppie T, Belda-Iniesta C, Ramírez de Molina V, Cejas P, et al. A critical role for choline kinase-alpha in the aggressiveness of bladder carcinomas. Oncogene (2009) 28:2425-35. doi:10.1038/ onc. 2009.91

18. Trousil S, Lee P, Pinato DJ, Ellis JK, Dina R, Aboagye EO, et al. Alterations of choline phospholipid metabolism in endometrial cancer are caused by choline kinase alpha overexpression and a hyperactivated deacylation pathway. Cancer Res (2014) 74:6867-77. doi:10.1158/0008-5472.CAN13-2409 
19. Xiong J, Bian J, Wang L, Zhou JY, Wang Y, Zhao Y, et al. Dysregulated choline metabolism in T-cell lymphoma: role of choline kinase-alpha and therapeutic targeting. Blood Cancer J (2015) 5:287. doi:10.1038/bcj.2015.10

20. Ramirez de Molina A, Sarmentero-Estrada J, Belda-Iniesta C, Taròn M, Ramirez de Molina V, Cejas P, et al. Expression of choline kinase alpha to predict outcome in patients with early-stage non-small-cell lung cancer: a retrospective study. Lancet Oncol (2007) 8:889-97. doi:10.1016/S1470-2045(07) 70279-6

21. Kwee SA, Hernandez B, Chan O, Wong L. Choline kinase alpha and hexokinase-2 protein expression in hepatocellular carcinoma: association with survival. PLoS One (2012) 7:e46591. doi:10.1371/journal.pone.0046591

22. Challapalli A, Trousil S, Hazell S, Kozlowski K, Gudi M, Aboagye EO, et al. Exploiting altered patterns of choline kinase-alpha expression on human prostate tissue to prognosticate prostate cancer. J Clin Pathol (2015) 68:703-9. doi:10.1136/jclinpath-2015-202859

23. Podo F, Sardanelli F, Iorio E, Canese R, Carpinelli G, Fausto A. Abnormal choline phospholipid metabolism in breast and ovary cancer: molecular bases for noninvasive imaging approaches. Curr Med Imaging Rev (2007) 3:123-37. doi:10.2174/157340507780619160

24. Glunde K, Penet MF, Jiang L, Jacobs MA, Bhujwalla ZM. Choline metabolism-based molecular diagnosis of cancer: an update. Expert Rev Mol Diagn (2015) 15:735-47. doi:10.1586/14737159.2015.1039515

25. Kumar M, Arlauckas SP, Saksena S, Verma G, Ittyerah R, Pickup S, et al. Magnetic resonance spectroscopy for detection of choline kinase inhibition in the treatment of brain tumors. Mol Cancer Ther (2015) 14:899-908. doi:10.1158/1535-7163.MCT-14-0775

26. Mignion L, Danhier P, Magat J, Porporato PE, Masquelier J, Gregoire V, et al. Non-invasive in vivo imaging of early metabolic tumor response to therapies targeting choline metabolism. Int J Cancer (2015) 138:2043-9. doi:10.1002/ ijc. 29932

27. Bernard NJ. Rheumatoid arthritis: choline kinase-more than a cancer therapy target? Nat Rev Rheumatol (2014) 10:699. doi:10.1038/nrrheum. 2014.180

28. Guma M, Sanchez-Lopez E, Lodi A, Garcia-Carbonell R, Tiziani S, Karin M, et al. Choline kinase inhibition in rheumatoid arthritis. Ann Rheum Dis (2014) 74:1399-407. doi:10.1136/annrheumdis-2014-205696

29. Yalcin A, Clem B, Makoni S, Clem A, Nelson K, Thornburg J, et al. Selective inhibition of choline kinase simultaneously attenuates MAPK and PI3K/AKT signaling. Oncogene (2010) 29:139-49. doi:10.1038/onc.2009.317

30. Glunde K, Raman V, Mori N, Bhujwalla ZM. RNA interference-mediated choline kinase suppression in breast cancer cells induces differentiation and reduces proliferation. Cancer Res (2005) 65:11034-43. doi:10.1158/00085472.CAN-05-1807

31. Mori N, Glunde K, Takagi T, Raman V, Bhujwalla ZM. Choline kinase down-regulation increases the effect of 5 -fluorouracil in breast cancer cells. Cancer Res (2007) 67:11284-90. doi:10.1158/0008-5472.CAN-07-2728

32. Lacal JC. Choline kinase: a novel target for antitumor drugs. IDrugs (2001) 4:419-26.

33. Janardhan S, Srivani P, Sastry GN. Choline kinase: an important target for cancer. Curr Med Chem (2006) 13:1169-86. doi:10.2174/092986706776360923

34. de la Cueva A, Ramirez de Molina A, Avarez-Ayerza N, Ramos MA, Cebrian A, Del Pulgar TG, et al. Combined 5-FU and ChoKalpha inhibitors as a new alternative therapy of colorectal cancer: evidence in human tumor-derived cell lines and mouse xenografts. PLoS One (2013) 8:e64961. doi:10.1371/journal. pone.0064961

35. Sanchez-Lopez E, Zimmerman T, del PT, Moyer MP, Lacal Sanjuan JC, Cebrian A. Choline kinase inhibition induces exacerbated endoplasmic reticulum stress and triggers apoptosis via $\mathrm{CHOP}$ in cancer cells. Cell Death Dis (2013) 4:e933. doi:10.1038/cddis.2013.453

36. Granata A, Nicoletti R, Tinaglia V, De Cecco L, Pisanu ME, Ricci A, et al. Choline kinase-alpha by regulating cell aggressiveness and drug sensitivity is a potential druggable target for ovarian cancer. Br J Cancer (2014) 110:330-40. doi:10.1038/bjc.2013.729

37. Granata A, Nicoletti R, Perego P, Iorio E, Krishnamachary B, Benigni F, et al. Global metabolic profile identifies choline kinase alpha as a key regulator of glutathione-dependent antioxidant cell defense in ovarian carcinoma. Oncotarget (2015) 6:11216-30. doi:10.18632/oncotarget.3589
38. Kim HS, Tian L, Jung M, Choi SK, Sun Y, Kim H, et al. Downregulation of choline kinase-alpha enhances autophagy in tamoxifen-resistant breast cancer cells. PLoS One (2015) 10:e0141110. doi:10.1371/journal.pone. 0141110

39. Mazarico JM, Sanchez-Arevalo Lobo V, Favicchio R, Greenhalf W, Costello E, Carrillo-de Santa PE, et al. Choline kinase alpha (CHKalpha) as a therapeutic target in pancreatic ductal adenocarcinoma: expression, predictive value, and sensitivity to inhibitors. Mol Cancer Ther (2016) 15:323-33. doi:10.1158/15357163.MCT-15-0214

40. Asim M, Massie CE, Orafidiya F, Pertega-Gomes N, Warren AY, Esmaeili M, et al. Choline kinase alpha as an androgen receptor chaperone and prostate cancer therapeutic target. J Natl Cancer Inst (2016) 108:ii:djv371. doi:10.1093/ jnci/djv371

41. Hernandez-Alcoceba R, Saniger L, Campos J, Nunez MC, Khaless F, Gallo MA, et al. Choline kinase inhibitors as a novel approach for antiproliferative drug design. Oncogene (1997) 15:2289-301. doi:10.1038/sj.onc.1201414

42. Hernandez-Alcoceba R, Fernandez F, Lacal JC. In vivo antitumor activity of choline kinase inhibitors: a novel target for anticancer drug discovery. Cancer Res (1999) 59:3112-8.

43. Lacal JC, Campos JM. Preclinical characterization of RSM-932A, a novel anticancer drug targeting the human choline kinase alpha, an enzyme involved in increased lipid metabolism of cancer cells. Mol Cancer Ther (2015) 14:31-9. doi:10.1158/1535-7163.MCT-14-0531

44. Clem BF, Clem AL, Yalcin A, Goswami U, Arumugam S, Telang S, et al. A novel small molecule antagonist of choline kinase-alpha that simultaneously suppresses MAPK and PI3K/AKT signaling. Oncogene (2011) 30:3370-80. doi:10.1038/onc.2011.51

45. Zech SG, Kohlmann A, Zhou T, Li F, Squillace RM, Parillon LE, et al. Novel small molecule inhibitors of choline kinase identified by fragment-based drug discovery. J Med Chem (2016) 59:671-86. doi:10.1021/acs.jmedchem. $5 \mathrm{~b} 01552$

46. Jayson GC, Kohn EC, Kitchener HC, Ledermann JA. Ovarian cancer. Lancet (2014) 384:1376-88. doi:10.1016/S0140-6736(13)62146-7

47. Torre LA, Bray F, Siegel RL, Ferlay J, Lortet-Tieulent J, Jemal A. Global cancer statistics, 2012. CA Cancer J Clin (2015) 65:87-108. doi:10.3322/caac.21262

48. Vaughan S, Coward JI, Bast RC Jr, Berchuck A, Berek JS, Brenton JD, et al. Rethinking ovarian cancer: recommendations for improving outcomes. Nat Rev Cancer (2011) 11:719-25. doi:10.1038/nrc3144

49. Siegel RL, Miller KD, Jemal A. Cancer statistics, 2015. CA Cancer J Clin (2015) 65:5-29. doi:10.3322/caac.21254

50. Spadaro F, Ramoni C, Mezzanzanica D, Miotti S, Alberti P, Cecchetti S, et al. Phosphatidylcholine-specific phospholipase $\mathrm{C}$ activation in epithelial ovarian cancer cells. Cancer Res (2008) 68:6541-9. doi:10.1158/0008-5472. CAN-07-6763

51. Chua BT, Gallego-Ortega D, de Molina A, Ullrich A, Lacal JC, Downward J. Regulation of Akt(ser473) phosphorylation by Choline kinase in breast carcinoma cells. Mol Cancer (2009) 8:131. doi:10.1186/1476-4598-8-131

52. Singh S, Khan AR, Gupta AK. Role of glutathione in cancer pathophysiology and therapeutic interventions. J Exp Ther Oncol (2012) 9:303-16.

53. Godwin AK, Meister A, O'D wyer PJ, Huang CS, Hamilton TC, Anderson ME. High resistance to cisplatin in human ovarian cancer cell lines is associated with marked increase of glutathione synthesis. Proc Natl Acad Sci U S A (1992) 89:3070-4. doi:10.1073/pnas.89.7.3070

54. Chen HH, Kuo MT. Role of glutathione in the regulation of cisplatin resistance in cancer chemotherapy. Met Based Drugs (2010) 2010:430939. doi:10.1155/2010/430939

55. Shim GS, Manandhar S, Shin DH, Kim TH, Kwak MK. Acquisition of doxorubicin resistance in ovarian carcinoma cells accompanies activation of the NRF2 pathway. Free Radic Biol Med (2009) 47:1619-31. doi:10.1016/j. freeradbiomed.2009.09.006

56. Stewart JD, Marchan R, Lesjak MS, Lambert J, Hergenroeder R, Ellis JK, et al. Choline-releasing glycerophosphodiesterase EDI3 drives tumor cell migration and metastasis. Proc Natl Acad Sci U S A (2012) 109:8155-60. doi:10.1073/ pnas. 1117654109

57. Lesjak MS, Marchan R, Stewart JD, Rempel E, Rahnenführer J, Hengstler JG EDI3 links choline metabolism to integrin expression, cell adhesion and spreading. Cell Adh Migr (2014) 8:499-508. doi:10.4161/cam.29284 
58. Raj L, Ide T, Gurkar AU, Foley M, Schenone M, Li X, et al. Selective killing of cancer cells by a small molecule targeting the stress response to ROS. Nature (2011) 475:231-4. doi:10.1038/nature10167

59. Challapalli A, Aboagye EO. Positron emission tomography imaging of tumor cell metabolism and application to therapy response monitoring. Front Oncol (2016) 6:44. doi:10.3389/fonc.2016.00044

60. Fanti S, Nanni C, Ambrosini V, Gross MD, Rubello D, Farsad M. PET in genitourinary tract cancers. Q J Nucl Med Mol Imaging (2007) 51(3):260-71.

61. Torizuka T, Kanno T, Futatsubashi M, Okada H, Yoshikawa E, Nakamura F, et al. Imaging of gynecologic tumors: comparison of (11)C-choline PET with (18)F-FDG PET. J Nucl Med (2003) 44(7):1051-6.
Conflict of Interest Statement: The authors declare that the research was conducted in the absence of any commercial or financial relationships that could be construed as a potential conflict of interest.

Copyright $\odot 2016$ Bagnoli, Granata, Nicoletti, Krishnamachary, Bhujwalla, Canese, Podo, Canevari, Iorio and Mezzanzanica. This is an open-access article distributed under the terms of the Creative Commons Attribution License (CC BY). The use, distribution or reproduction in other forums is permitted, provided the original author(s) or licensor are credited and that the original publication in this journal is cited, in accordance with accepted academic practice. No use, distribution or reproduction is permitted which does not comply with these terms. 